\title{
Supervisão em Serviços-Escola de Psicologia no Brasil: Perspectivas dos Supervisores e Estagiários
}

\author{
Margareth da Silva Oliveira \\ Pontifícia Universidade Católica do Rio Grande do Sul \\ Porto Alegre, RS, Brasil \\ Rodrigo Fernando Pereira \\ Universidade de São Paulo \\ São Paulo, SP, Brasil \\ Ana Claudia Azevedo Peixoto \\ Universidade Federal do Rio de Janeiro \\ Rio de Janeiro, RJ, Brasil \\ Marina Monzani da Rocha \\ Universidade Paulista \\ São Paulo, SP, Brasil \\ Nancy Ramacciotti de Oliveira-Monteiro \\ Universidade Federal de São Paulo \\ São Paulo, SP, Brasil \\ Mônica Medeiros Kother Macedo \\ Pontificia Universidade Católica do Rio Grande do Sul \\ Porto Alegre, RS, Brasil \\ Edwiges Ferreira de Mattos Silvares \\ Universidade de São Paulo \\ São Paulo, SP, Brasil

\section{RESUMO}

Embora nos últimos 20 anos tenha havido um aumento do interesse pela caracterização da clientela e descrição do funcionamento dos serviços-escola de Psicologia, pouca atenção tem sido dada ao processo de supervisão que ocorre nesses centros. A supervisão no contexto clínico tem como característica fundamental contemplar, ao mesmo tempo, aspectos relativos ao aprendizado e aspectos relacionados à relação terapêutica. Neste trabalho, foi utilizado um instrumento que avaliava a supervisão de acordo com os fatores empatia, aprimoramento do aprendizado e compreensão. O questionário, desenvolvido em duas versões, foi respondido online por 126 supervisores e 238 estagiários de Psicologia de diversas regiões do país. Verificou-se que a supervisão é, de forma geral, bem avaliada tanto por supervisores como por supervisionandos, embora existam algumas discrepâncias significativas na visão dos dois grupos.

Palavras-chave: Supervisão clínica; clínicas-escola; ensino da psicologia.

\section{ABSTRACT}

Supervision in Brazilian Psychology University Services: Supervisors and Residents'Perspectives

In the last 20 years, there has been an increasing interest in the functioning of psychology university clinics, mainly regarding its clientele. However, there has been little interest in the supervision in this context. Clinical supervision is a process that involves aspects from teaching as well from the therapeutic alliance. In this study, an instrument was used that assess the supervision according to the factors empathy, learning enhancement and comprehension. In total, 126 supervisors and 238 psychology students from several Brazilian regions answered an online questionnaire in order to evaluate supervision. In general, the supervision had a good evaluation from both supervisors and students. However, there were some discrepancies in specific points between the two groups.

Keywords: Clinical supervision; school-clinics; psychology education.

\section{RESUMEN}

Supervisión en Servicios-Escuela de Psicología en el Brazil: Perspectivas de los Supervisores y los Pasantes Aunque en los últimos 20 años ha habido un creciente interés en la caracterización y descripción del funcionamiento de los servicios-escuela de psicología, poca atención es dada al proceso de supervisión que ocurre en estos centros. La supervisión en el ámbito clínico tiene como una característica fundamental contener, al mismo tiempo, los aspectos relativos a la aprendizajen y los aspectos relacionados con la relación terapéutica. En este trabajo se utilizó un instrumento que evaluó el supervisor de acuerdo con los factores empatía, mejora del aprendizaje y comprensión. El cuestionario, desarrollado en dos versiones, fue respondido online por 126 supervisores y 238 pasantes de psicología en distintas regiones del país. Se verificó que la supervisión es, en general, bien evaluada tanto por los supervisores como por los supervisados, aunque haya algunas discrepancias significativas en la percepción de los dos grupos.

Palabras clave: Supervision clínica; escuelas clínicas; enseñanza de psicologia. 


\section{SUPERVISÃO EM SERVIÇOS-ESCOLA DE PSICOLOGIA NO BRASIL: PERSPECTIVAS DOS SUPERVISORES E ESTAGIÁRIOS}

Amparados por uma legislação que criou e regulamentou a profissão da Psicologia, os serviçosescola têm um papel fundamental como campo de experiência, treinamento e qualificação profissional em todos seus âmbitos essenciais, a saber, teóricos, técnicos e éticos (Löhr \& Silvares, 2006; Macedo \& Dockhorn, 2009). A supervisão dos estágios realizados nesses serviços é um dos importantes pilares que sustentam esse campo de formação do futuro psicólogo.

A literatura sobre supervisão é variada, especialmente de acordo com a abordagem dos autores das publicações sobre o tema, de modo que definir e descrever o processo de supervisão é uma tarefa complexa. Ainda assim, é possível estabelecer reflexões partir de alguns consensos e aspectos complementares presentes nos textos sobre o assunto. Um desses consensos é de que a supervisão em Psicologia clínica, em especial em sua circunscrição supervisão de estágios próprios da formação, envolve um aspecto de treino - ou aprendizado - e outro de relacionamento, que muitos autores descrevem como similares à psicoterapia. Aguirre (2000), por exemplo, enfatiza o caráter terapêutico da supervisão, destacando como funções do supervisor a orientação e respaldo aos alunos supervisionados no tocante aos receios despertados no trabalho de atendimentos psicológicos. Macedo e Dockhorn (2009) afirmam que o supervisor ocupa a função daquele que, por estar fora do contexto do atendimento propriamente dito, exerce a capacidade de utilizar sua própria experiência clínica como recurso de ensino e de aprimoramento da capacidade do supervisionando em compreender a demanda do paciente. Boeckel, et al. (2010), por sua vez, apontam a importância da atividade de supervisão no serviço-escola e ressaltam que o acompanhamento, orientação e avaliação fornecidos pelos supervisores permitem que os acadêmicos estagiários sistematizem e avaliem suas intervenções.

São vários os autores que concordam com a importância das experiências oferecidas aos supervisionandos pelos serviços-escola de cursos de graduação em Psicologia. Esses serviços são, em geral, configurados por diferentes modalidades de atuação no âmbito da Psicologia, o que permite um potencial de ampliação das possibilidades de estratégias didáticopedagógicas para fundamentar o exercício profissional em diferentes contextos (Boeckel et al., 2010).

Embora os trabalhos sobre supervisão considerem a relevância dos aspectos de aprendizado e de relacionamento entre supervisor e supervisionando, aparentemente a ênfase dada a cada um desses pontos varia de acordo com a abordagem empregada. Autores de vertentes psicodinâmicas, por exemplo, ressaltam aspectos da relação entre supervisor supervisionando, enquanto autores ligados à terapia cognitivocomportamental (TCC) voltam-se primordialmente para as habilidades a serem adquiridas. Pretorius (2006), ainda como exemplo, descreve que os dois objetivos da supervisão em TCC são "ajudar o terapeuta a adotar a filosofia da TCC como a abordagem básica para alterar cognições, emoções e comportamentos do cliente (...) e ensinar ao terapeuta técnicas e habilidades específicas" (p. 414), excluindo assim, qualquer menção à relação entre supervisor e supervisionando. Para Dobson e Shaw (1993), a característica mais importante para um terapeuta cognitivo é a capacidade de estabelecer relações calorosas, com senso de cuidado e empatia. Adicionalmente, os autores defendem que esses aspectos são difíceis de alterar, devendo ser considerados um aspecto na seleção dos terapeutas, e não do treinamento o qual deve ser focado em questões técnicas e de habilidade relativos à abordagem.

Por sua vez, uma visão de supervisão a partir de abordagem centrada na pessoa envolve "transmitir ensinamentos básicos, mas, principalmente, fazer com que cada estagiário olhe para dentro de si, para a relação que estabelece com seu cliente e para o vínculo que desenvolve com seu supervisor" (Tavora, 2002, p. 121). Num outro vértice, no que diz respeito ao enfoque psicanalítico, Macedo e Dockhorn (2009) consideram que o desafio da supervisão contempla o próprio desafio da clínica psicanalítica, ou seja, fugir de um saber padronizado e preestabelecido em relação ao outro como meio de evitar a constatação da exigência que implica o contato com o padecimento psíquico (p. 213).

Percebe-se, portanto, como a visão da supervisão pode variar de acordo com a abordagem teórica do supervisor. Esse aspecto foi confirmado pelo estudo de Freitas e Noronha (2007) que levantou características que os supervisores consideravam mais ou menos importantes e relevantes em seus supervisionandos, de acordo com a abordagem utilizada. Nesse estudo, ficou indicado consenso entre supervisores de diferentes abordagens quanto à maior importância de certos aspectos como interesse, raciocínio clínico e ética. Também houve concordância em relação a pouca importância dada ao não dogmatismo e à produção científica. Por outro lado, alguns pontos específicos tiveram mais destaque de acordo com a abordagem. A terapia pessoal foi mais valorizada na abordagem psicanalítica, por exemplo, enquanto a empatia 
foi considerada fundamental para supervisores da abordagem centrada na pessoa.

Diversos trabalhos têm se dedicado à temática da supervisão em esferas clínicas. Nigam, Cameron e Leverette (1997) voltaram-se para a questão dos impasses na supervisão, avaliando a satisfação de residentes de curso de medicina com seus supervisores. Para isso, foi desenvolvido um questionário para avaliação de diversos aspectos da supervisão, em especial pontos indicativos de impasse ou desenvolvimento pobre. Os autores agruparam os resultados em três fatores (empatia e atenção à experiência afetiva do estagiário; habilidade de aprimorar o aprendizado e encorajar a autoexpressão; e compreensão das dificuldades e responsividade às necessidades do estagiário), indicando a possibilidade de se avaliar esses três aspectos da supervisão através do instrumento. De maneira geral, nesse estudo, os supervisores foram bem avaliados, sendo que os autores destacaram a empatia e o apoio, por parte do supervisor, como elementos favorecedores de um ambiente adequado para o aprendizado.

Uma adaptação desse instrumento canadense foi utilizada no Brasil em um estudo realizado com 56 alunos do nono semestre de um curso de Psicologia (Oliveira-Monteiro \& Nunes, 2008). As autoras dividiram o instrumento em duas dimensões: afetivorelacional e fatores sugestivos de linha teórica. Em relação ao primeiro aspecto, verificou-se que houve grande positividade em relação à imagem do supervisor, devidas, segundo as autoras, a possíveis idealizações por parte dos alunos. Não houve, por outro lado, relação entre a linha teórica e a boa imagem do supervisor.

Um estudo realizado através de questionários online com 132 supervisionandos (Cheon, Blumer, Shih, Murphy, \& Sato, 2009) investigou a relação entre uma medida de resultado - satisfação com a supervisão - com possíveis variáveis preditoras, comparando os supervisores de acordo com a abordagem teórica. O trabalho mostrou que o fator que obteve maior relação com a satisfação do estagiário com a supervisão foi a relação estabelecida com o supervisor, em especial a aliança de trabalho. Surpreendentemente, as combinações de aspectos demográficos ou de orientação teórica não foram relevantes para a satisfação. Ou seja, o fato de supervisor e estagiário compartilharem características comuns, como a abordagem, não foi fundamental para a boa avaliação da supervisão, o que vai ao encontro do observado por Oliveira-Monteiro e Nunes (2008). Houve, no entanto, maior satisfação de supervisionandos com a supervisão realizada na esfera particular quando comparada àquela realizada na academia.
Barreto e Barleta (2010) realizaram um estudo que teve como objetivo conhecer as perspectivas do supervisor e do supervisionando a respeito do processo de supervisão e suas peculiaridades. As autoras constataram que para ambos (supervisor e supervisionando), a supervisão deve ter como objetivo a facilitação da prática profissional fomentada por meio de várias estratégias didáticas. Um dos aspectos destacados nesse estudo diz respeito ao fato de que o pouco tempo de supervisão, o excesso de atendimentos e a interferência institucional foram citados por supervisores e supervisionandos como dificuldades referentes à atividade de supervisão.

A diversidade de aspectos envolvidos na supervisão leva à constatação da relevância de que se busque investigar peculiaridades próprias a tal atividade realizada nos serviços-escola de Psicologia no país. Desde que Ancona-Lopez (1981) realizou seu levantamento sobre os atendimentos realizados nos serviços universitários de Psicologia, o tema tem recebido maior interesse científico. Um dos aspectos mais investigados é a caracterização da clientela, como mostram estudos realizados na Universidade São Francisco (Romaro \& Capitão, 2003), na Universidade Federal de Uberlândia (Melo \& Perfeito, 2006) e na Pontificia Universidade Católica do Rio Grande do Sul (Campezatto \& Nunes, 2007; Macedo, Nunes, Campezatto, \& Padilha, 2009; Macedo, Silva, Giaretta, Ribas, \& Druck, 2010; Macedo et al., 2011). Trabalho de identificação da clientela com foco na prevenção também é encontrado em Silvares (1993). No entanto, a questão da supervisão de estágios específica da graduação recebe ainda pouca atenção direta, surgindo apenas marginalmente nas publicações relacionadas aos serviços-escola de Psicologia. Nessa perspectiva, que aponta necessidades ainda presentes quanto à melhor clarificação do processo de supervisão, especialmente no cenário nacional, insere-se o presente trabalho cujo objetivo foi identificar impressões, tanto de supervisores como de supervisionandos, sobre a supervisão em serviços-escola de cursos de graduação de Psicologia, no Brasil.

\section{MÉTODO}

\section{Amostra}

Foram incluídos no estudo supervisores e estagiários de cursos de Psicologia brasileiros. Após a exclusão dos questionários incompletos, foram estudados respostas de 126 supervisores, com idade média de 43,7 anos ( $\mathrm{DP}=11,22)$. A maioria desses pesquisados era do sexo feminino $(74,5 \%)$, da região sudeste $(50,8 \%)$, seguida, em frequência, pela região 
sul $(31,7 \%)$, nordeste $(7,5 \%)$, norte e centro-oeste (5\% cada).

Por sua vez, após a exclusão das respostas parciais nos questionários dos estagiários, somaram-se mais 238 participantes, com idade média de 25,9 anos $(\mathrm{DP}=7,64)$. Esses estagiários eram predominantemente do sexo feminino $(84,3 \%)$, pertencentes à região sudeste $(38,8 \%)$, região centro-oeste $(30,8 \%)$, sul $(17,6 \%)$, nordeste $(8,4 \%)$ e norte $(4,4 \%)$.

\section{Instrumentos}

Para avaliar a qualidade da supervisão do ponto de vista do supervisor e do estagiário, foram utilizadas duas versões adaptadas do questionário de impasses na supervisão de psicoterapia (Nigam, Cameron, $\&$ Leverette, 1997). Inicialmente foi realizada uma tradução direta da versão canadense, voltada para a perspectiva dos estagiários, seguida de adaptações com adequações das mesmas questões voltadas para a perspectiva dos supervisores. Ambas as versões foram submetidas à apreciação do grupo de professores da Associação Nacional de Pesquisa e Pós-Graduação em Psicologia (ANPEPP) responsável pela pesquisa "Serviços-Escola de Psicologia", sendo provadas após alterações consensuais. Foi realizado back translation do instrumento, a fim de garantir maior validade.

QUADRO 1

Questionário na versão para o estagiário (adaptação de Nigam, Cameron, \& Leverette,1997)

Responda considerando a seguinte escala: $\mathrm{N}$ - Nunca $\mathrm{R}$ - Raramente $50 \%$ - $50 \%$ das vezes $\quad$ F - Frequentemente $\mathrm{S}$ - Sempre

Marque com um X o quadrante equivalente à resposta que lhe parece mais adequada, considerando a maioria de seus supervisores.

\begin{tabular}{|c|c|c|c|c|c|}
\hline QUESTÕES & $N$ & $R$ & $50 \%$ & $F$ & $S$ \\
\hline \multicolumn{6}{|l|}{ 1. Seu supervisor apoia seu desejo de aprender? } \\
\hline \multicolumn{6}{|l|}{ 2. Seu supervisor ajusta seus conhecimentos para seu nível de treinamento e experiência? } \\
\hline \multicolumn{6}{|l|}{ 3. Você descreveria seu supervisor como um bom modelo? } \\
\hline \multicolumn{6}{|l|}{ 4. Você se sente respeitado pelo seu supervisor? } \\
\hline \multicolumn{6}{|l|}{ 5. O seu supervisor aceita os erros que você faz? } \\
\hline \multicolumn{6}{|l|}{ 6. O quanto você se sente criticado pelo seu supervisor? } \\
\hline \multicolumn{6}{|l|}{ 7. Você se sente compreendido pelo seu supervisor? } \\
\hline \multicolumn{6}{|l|}{ 8. Com que frequência seu supervisor impõe a você sua própria "prescrição psicoterapêutica"? } \\
\hline \multicolumn{6}{|l|}{ 9. Seu(s) supervisor(es) está(ao) disponíveis quando ocorre alguma crise com seu paciente? } \\
\hline \multicolumn{6}{|l|}{ 10. Você se sente obrigado a concordar com as ideias e pensamentos de seu supervisor? } \\
\hline \multicolumn{6}{|l|}{ 11. Alguma vez você ficou chateado com seu supervisor porque ele não lhe apoiou emocionalmente? } \\
\hline \multicolumn{6}{|l|}{$\begin{array}{l}\text { 12. O seu supervisor lhe dá exemplos de seus próprios pacientes para ajudá-lo a lidar com os } \\
\text { dilemas dos seus pacientes? }\end{array}$} \\
\hline \multicolumn{6}{|l|}{$\begin{array}{l}\text { 13. O seu supervisor encoraja a exploração de aspectos pessoais mobilizados pela interação com } \\
\text { o paciente que possam interferir no processo psicoterapêutico? }\end{array}$} \\
\hline \multicolumn{6}{|l|}{$\begin{array}{l}\text { 14. Com que frequência você lembra de uma situação em que o tratamento de um paciente não } \\
\text { progrediu por mais de } 3-4 \text { semanas? }\end{array}$} \\
\hline \multicolumn{6}{|l|}{$\begin{array}{l}\text { 15. Com que frequência você lembra que a supervisão de um paciente não trouxe nenhuma } \\
\text { informação nova por mais de } 3 \text { ou } 4 \text { semanas? }\end{array}$} \\
\hline \multicolumn{6}{|l|}{ 16. Com que frequência você sente que aprendeu algo na supervisão? } \\
\hline \multicolumn{6}{|l|}{ 17. Com que frequência pediu para que você preparasse supervisão verbalmente ou por escrito? } \\
\hline \multicolumn{6}{|l|}{ 18. Quão livre você é para expressar uma opinião diferente da de seu supervisor? } \\
\hline \multicolumn{6}{|l|}{ 19. Com que frequência você sentiu o supervisor invadindo sua vida pessoal? } \\
\hline \multicolumn{6}{|l|}{ 20. Alguma vez você se sentiu envergonhado ou humilhado pelos comentários do seu supervisor? } \\
\hline \multicolumn{6}{|l|}{$\begin{array}{l}\text { 21. O seu supervisor lhe ajuda com seus dilemas dizendo algo do tipo "o que eu faria nesta } \\
\text { situação é isto...”? }\end{array}$} \\
\hline \multicolumn{6}{|l|}{$\begin{array}{l}\text { 22. Com que frequência você sentiu que seu supervisor era "só trabalho" e deixou pouco espaço } \\
\text { para trocas mais informais? }\end{array}$} \\
\hline \multicolumn{6}{|l|}{$\begin{array}{l}\text { 23. Com que frequência você teve a experiência com um supervisor que tinha uma ideia } \\
\text { pré-estabelecida de que as coisas devem ser feitas apenas da sua maneira? }\end{array}$} \\
\hline \multicolumn{6}{|l|}{ 24. Alguma vez você se achou na posição de ter de "fincar o pé" contra seu supervisor? } \\
\hline \multicolumn{6}{|l|}{$\begin{array}{l}\text { 25. Alguma vez você se percebeu não dizendo o que realmente acontecia na terapia (atendimento) } \\
\text { do seu paciente? }\end{array}$} \\
\hline \multicolumn{6}{|l|}{ 26. Você acha que seu supervisor é fundamentalmente um crítico de seu trabalho? } \\
\hline \multicolumn{6}{|l|}{ 27. Você sente que seu supervisor tem confiança nas suas habilidades como psicoterapeuta? } \\
\hline $\begin{array}{l}\text { 28. O seu supervisor faz demonstrações práticas de intervenção, tais como apresentação de filmes } \\
\text { ou de transcrições de sessões terapêuticas? }\end{array}$ & & & & & \\
\hline
\end{tabular}


QUADRO 2

Questionário na versão para o supervisor (adaptação de Nigam, Cameron, \& Leverette, 1997)

\begin{tabular}{|c|c|c|c|c|c|}
\hline QUESTÕES & $N$ & $R$ & $50 \%$ & $F$ & $S$ \\
\hline 1. Você apoia o desejo de aprender dos alunos/supervisionandos? & & & & & \\
\hline 2. Você ajusta seus conhecimentos para o nível de treinamento e experiência de seus alunos? & & & & & \\
\hline 3. Você se vê como bom modelo aos seus alunos/supervisionandos? & & & & & \\
\hline 4. Você respeita seus alunos/supervisionandos? & & & & & \\
\hline 5. Aceita os erros que os alunos/supervisionandos cometem? & & & & & \\
\hline 6. Você se sente criticado pelos alunos/supervisionandos? & & & & & \\
\hline 7. Compreende seus alunos/supervisionandos? & & & & & \\
\hline $\begin{array}{l}\text { 8. Com que frequência impõe a seus alunos/supervisionandos suas própria ideias ou "prescrição } \\
\text { psicoterapêutica"? }\end{array}$ & & & & & \\
\hline $\begin{array}{l}\text { 9. Está disponível para esclarecer dúvidas de alunos ou para auxiliar ocorrências de crises com } \\
\text { pacientes de seus supervisionandos? }\end{array}$ & & & & & \\
\hline $\begin{array}{l}\text { 10. Obriga alunos/supervisionandos a concordarem com suas ideias, pensamentos e orientações } \\
\text { didáticas e/ou de supervisão? }\end{array}$ & & & & & \\
\hline 11. Aborrece-se com alunos/supervisionandos por não o apoiarem emocionalmente ou às suas ideias? & & & & & \\
\hline $\begin{array}{l}\text { 12. Dá exemplos acerca de seus próprios pacientes para ajudar a lidar com os dilemas dos seus } \\
\text { alunos/supervisionandos? }\end{array}$ & & & & & \\
\hline $\begin{array}{l}\text { 13. Encoraja a exploração de aspectos contratransferenciais (aspectos pessoais mobilizados pela } \\
\text { interação com o paciente que possam interferir no processo psicoterapêutico)? }\end{array}$ & & & & & \\
\hline $\begin{array}{l}\text { 14. Você se lembra, em aulas ou supervisões, de situações em que o tratamento de um paciente não } \\
\text { progrediu por mais de } 3-4 \text { semanas? }\end{array}$ & & & & & \\
\hline $\begin{array}{l}\text { 15. Com que frequência você lembra que a supervisão de um paciente não trouxe nenhuma } \\
\text { informação nova por mais de } 3 \text { ou } 4 \text { semanas? }\end{array}$ & & & & & \\
\hline 16. Com que frequência você sente que ensinou algo em aula ou supervisão? & & & & & \\
\hline 17. Com que frequência você prepara aula ou supervisão verbalmente ou por escrito? & & & & & \\
\hline $\begin{array}{l}\text { 18. Quão livre você deixa seus alunos/supervisionandos para expressarem uma opinião diferente } \\
\text { da sua? }\end{array}$ & & & & & \\
\hline 19. Com que frequência você se sentiu invadindo a vida pessoal de seus alunos/supervisionandos? & & & & & \\
\hline $\begin{array}{l}\text { 20. Alguma vez você percebeu alunos/supervisionandos envergonhados ou humilhados pelos } \\
\text { seus comentários? }\end{array}$ & & & & & \\
\hline $\begin{array}{l}\text { 21. Você ajuda seus alunos/supervisionandos em seus dilemas dizendo algo do tipo "o que eu faria } \\
\text { nesta situação é isto..."? }\end{array}$ & & & & & \\
\hline $\begin{array}{l}\text { 22. Com que frequência sentiu que seu papel de professor/supervisor era "só trabalho" e deixou } \\
\text { pouco espaço para trocas mais informais? }\end{array}$ & & & & & \\
\hline $\begin{array}{l}\text { 23. Com que frequência você teve a experiência, como professor ou supervisor, que tinha uma ideia } \\
\text { pré-estabelecida de que as coisas devem ser feitas apenas da sua maneira? }\end{array}$ & & & & & \\
\hline 24. Alguma vez você se achou na posição de ter de "fincar o pé" contra seu aluno/supervisionando? & & & & & \\
\hline $\begin{array}{l}\text { 25. Alguma vez você se percebeu não dizendo o que realmente acontecia na terapia (atendimento) } \\
\text { dos seus pacientes? }\end{array}$ & & & & & \\
\hline 26. Você se acha fundamentalmente crítico de seu trabalho? & & & & & \\
\hline 27. Você sente confiança nas suas habilidades como psicoterapeuta? & & & & & \\
\hline $\begin{array}{l}\text { 28. Você faz demonstrações práticas de intervenção, tais como apresentação de filmes ou de } \\
\text { transcrições de sessões terapêuticas? }\end{array}$ & & & & & \\
\hline
\end{tabular}

Os questionários consistem em 28 questões que propõem situações relativas ao contexto de supervisão. No Quadro 1 encontra-se a versão do questionário aplicada nos estagiários. Em ambas as versões (estagiários/supervisores), os participantes devem assinalar numa escala Likert de cinco pontos, a frequência na qual a situação citada ocorre, sendo atribuídos, para fins de quantificação, os seguintes valores: nunca (1), raramente (2), às vezes (3), frequentemente (4) e sempre (5). Os autores da versão original indicaram três fatores pertinentes às questões do instrumento, relativos à empatia, aprimoramento do aprendizado e compreensão. Tanto a versão do supervisor (Quadro 2) quanto a do estagiário passaram por uma análise da sua consistência interna (Pereira, Marturano, Rocha, \& Silvares, no prelo), resultando em valores de Cronbach iguais a 0,751 e 0,869, respectivamente. Uma vez que o instrumento original foi desenhado para ser respondido por estagiários/ residentes, é esperado que a versão para os participantes estagiários tenha tido um índice maior de consistência interna. 


\section{Procedimento}

O questionário sobre impasses foi incluído como parte da pesquisa sobre serviços-escola de Psicologia no Brasil, cuja coleta de dados foi realizada online, através de preenchimento pelo próprio participante, gerando de forma automática o banco de dados da pesquisa. Os participantes foram convidados a integrar a pesquisa através de folhetos, comunicações eletrônicas ou anúncios em congressos e eventos de Psicologia. A participação se dava através da Internet, com cada participante acessando o site da pesquisa, identificandose e respondendo às perguntas, sequencialmente, num sistema programado previamente. Cada usuário do sistema era identificado pelo seu Cadastro de Pessoa Física (CPF) e recebia uma senha caso quisesse interromper a participação e retornar em outro momento. O termo de consentimento era apresentado antes das perguntas e o assentimento do mesmo era condição para a participação na pesquisa. $\mathrm{O}$ projeto foi aprovado por Comitê de Ética em Pesquisa (Parecer Of. 042/08 - CEPHIP/08/07/2008).

\section{Análise dos dados}

Os dados foram gerados pela plataforma online da pesquisa, que processou os dados dos respondentes em planilhas no formato SPSS 17.0. Foram excluídos os participantes que responderam apenas parcialmente ao questionário. As respostas aos questionários foram agrupadas em médias para cada uma das questões, tanto para os supervisores como estagiários. Esses valores médios foram, então, comparados de acordo com os grupos de estagiários ou supervisores através do teste de Mann-Whitney.

\section{RESULTADOS}

As Figuras 1, 2 e 3 mostram os valores médios e desvios padrão das respostas de cada uma das questões para estagiários, supervisores e, a título de ilustração, a comparação das respostas dos estagiários no estudo original, realizado no Canadá (Nigam, Cameron, \& Leverette, 1997). Lembrando que para cada resposta no questionário foi atribuído um valor (ex. nunca $=1 \mathrm{e}$ sempre $=5$ ), em seguida foram agrupados nas médias apresentadas nas figuras. Valores mais altos indicam maior frequência de ocorrência das situações e valores mais baixos indicam menor frequência. Os valores p no topo de cada figura indicam a significância estatística (a 5\%) da comparação entre estagiários e supervisores.

A Figura 1 apresenta os resultados referentes às questões do fator empatia, que se refere à capacidade do supervisor para entender as demandas do super- visionando. $\mathrm{O}$ fator empatia é composto pelas questões 2, 3, 4, 5, 6, 7, 19, 20, 22 e 26 (ver Quadro 1).

As questões 2, 3, 4, 5 e 7 (ver Quadro 1) descrevem situações positivas, ou seja, uma maior frequência indica melhor supervisão. Esses itens referem-se a avaliações diretas, por parte dos supervisionandos, em relação a quanto os supervisores são considerados empáticos, compreensivos, bons modelos e tolerantes. Observase que nessas questões as médias são mais altas do que as das questões $6,19,20,22$, que são negativas, e que a questão 26, ambígua em sua formulação. Nas questões nas quais há diferença estatística entre os supervisores e estagiários, os supervisores indicaram uma média de frequência maior do que as apontadas por estagiários, inclusive com uma diferença bastante significativa $(p<0,001)$, como ocorreu nas questões 2 e 4, nas quais os supervisores relataram com maior frequência ajustarem os ensinamentos para o nível de experiência dos estagiários e serem respeitosos na supervisão.

A Figura 2 apresenta os resultados referentes às questões do fator aprimoramento do aprendizado, que se refere a quanto o supervisor incentiva o aluno a desenvolver conhecimentos técnicos. O fator aprimoramento do aprendizado é composto pelas questões $1,8,10,12,13,16,17,18,25$ e 27 (ver Quadro 1).

Neste grupo de questões, apenas os itens 8, 10 e 25 (ver Quadro 1) são negativos, ou seja, indicam comportamentos inadequados na supervisão por parte do supervisor. Mais uma vez, as médias foram altas para as questões positivas e baixas para as questões

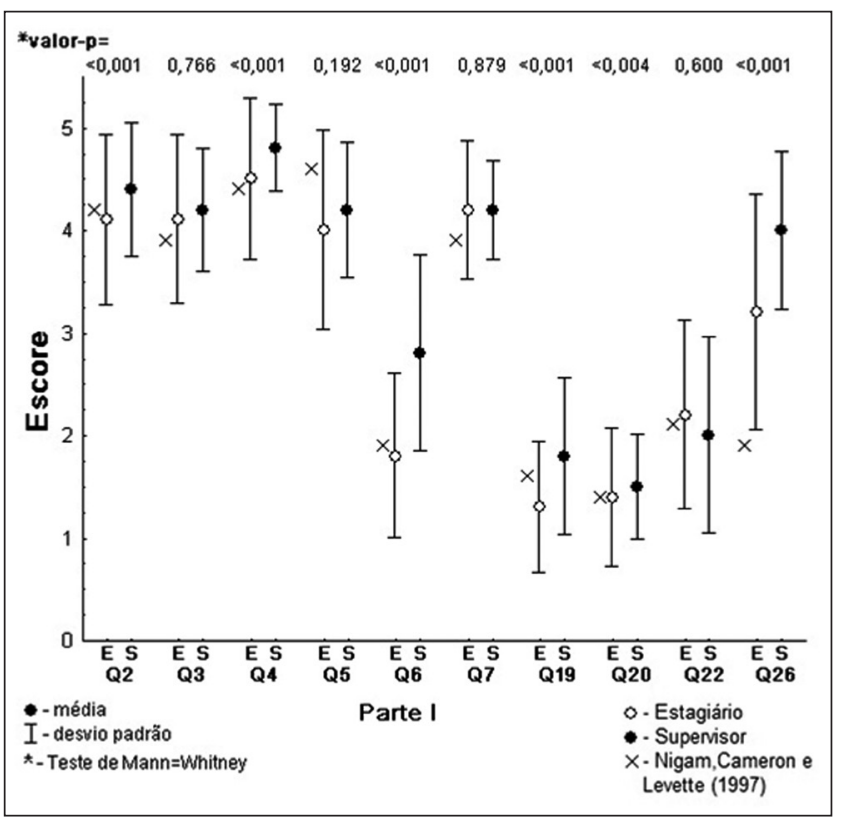

Figura 1. Valores médios das respostas de estagiários e supervisores nas questões do fator empatia 
negativas. Neste grupo, no entanto, não houve um padrão nas diferenças significativas de médias nas respostas de supervisores e estagiários. É digno de nota o valor $p<0,001$ nas questões 1 , mostrando que os supervisores consideram apoiar o desejo de aprender dos alunos mais do que estes avaliam (12), indicando que os alunos relatam mais frequência de

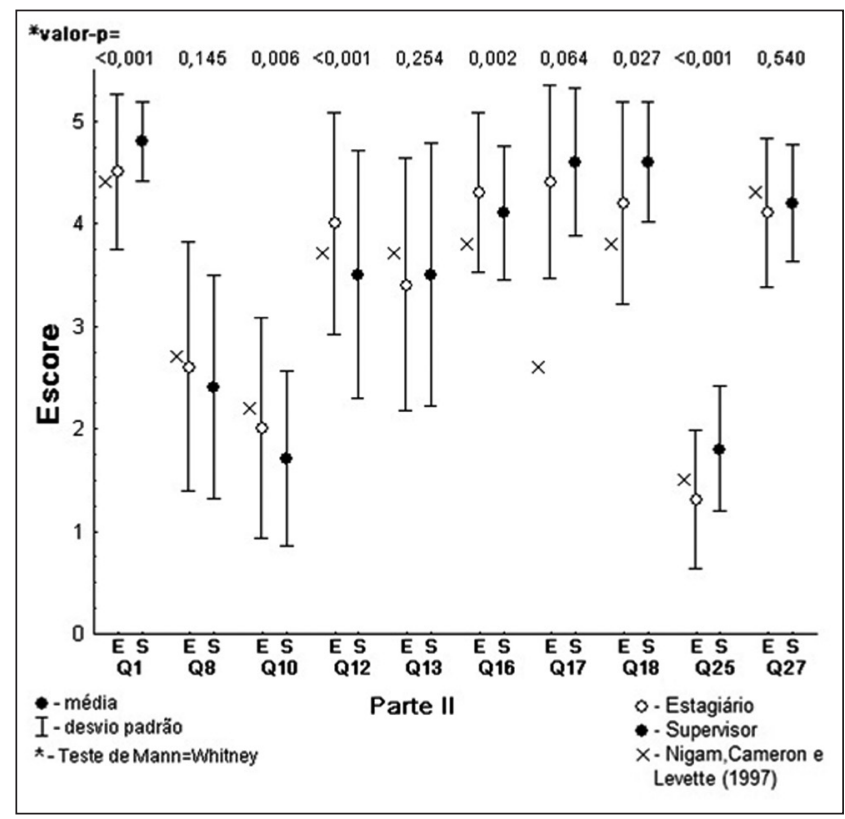

Figura 2. Valores médios das respostas de estagiários e supervisores nas questões do fator aprimoramento do aprendizado

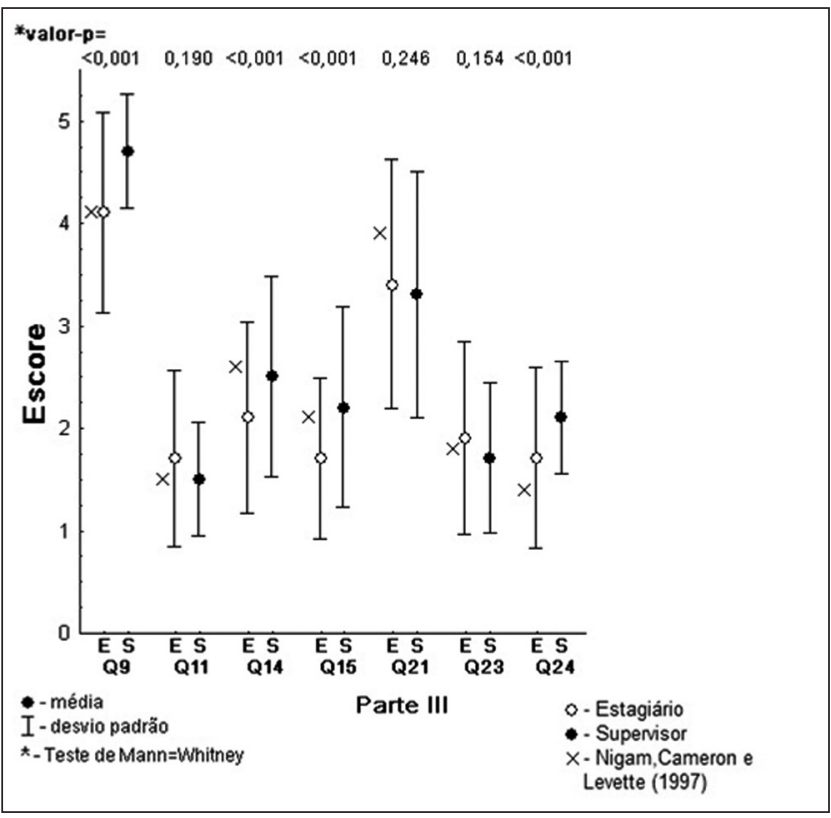

Figura 3. Valores médios das respostas de estagiários e supervisores nas questões do fator compreensão uso de exemplos dos pacientes dos supervisores do que estes mesmos relatam e (25), indicando que os alunos assumem com menor frequência esconder informações na supervisão do que os supervisores desconfiam. Outro ponto relevante é visível na questão 17 , indicando que os supervisores e estagiários brasileiros relatam maior freqüência no pedido de formulação de casos do que os estagiários canadenses.

Por fim, a Figura 3 engloba as questões 9, 11, 14, $15,21,23$ e 24, que se referem ao fator compreensão. Esse fator envolve situações em que o supervisionando passa por alguma dificuldade e avalia em que medida essas situações acontecem, bem como se o supervisor está apto ou disponível para lidar com esses problemas.

Nesse agrupamento, as questões 9 e 21 são positivas, e as outras negativas. Como ocorrido nos outros agrupamentos, as questões positivas tiveram maior média de freqüência do que as negativas. As diferenças estatisticamente significativas indicam que os supervisores se dizem mais disponíveis para crises do que os alunos relatam; que os supervisores percebem mais momentos de estagnação no andamento dos casos do que os estagiários e que os supervisores relataram mais ocorrências de oposição direta do que os estagiários.

\section{DISCUSSÃO}

Observou-se, de forma geral, que a supervisão é bem avaliada tanto por estagiários quanto por supervisores. As questões indicativas de boa supervisão diferenciaram-se das questões indicativas de supervisão inadequada, sendo que as primeiras tiveram os maiores valores médios, ao contrário das últimas. Esse resultado vai ao encontro do próprio trabalho que originou o questionário utilizado (Nigam, Cameron, \& Leverette, 1997) e de outro estudo que utilizou o mesmo questionário no Brasil, chegando a resultados semelhantes (Oliveira-Monteiro \& Nunes, 2008). O resultado obtido também se conforma ao de outro estudo realizado online que também demonstrou a satisfação dos estagiários com o processo de supervisão (Cheon, Blumer, Shih, Murphy, \& Sato, 2009).

Em relação ao exame mais detalhado dos dados, pode-se observar que os supervisores tenderam a se avaliar melhor do que a avaliação que lhes foi atribuída pelos estagiários nas questões do fator empatia. Nas questões dos outros fatores, não houve consistência na direção das diferenças entre as avaliações de um e outro grupo. Chama a atenção, também, o fato de que a questão na qual houve maior diferença entre as respostas de brasileiros e do estudo original foi 
em relação à formulação de casos, uma vez que os estudantes e supervisores do Brasil apontam uma alta frequência desse tipo de solicitação, enquanto os canadenses reportaram esse pedido como tendo baixa frequência. Isso pode se dever a uma variação na formação em ambos os países ou constituir um viés na amostra de um ou outro estudo.

Verificaram-se também diferenças nas medidas em que supervisores e alunos percebem a estagnação do andamento dos casos, sendo que os supervisores parecem mais sensíveis a essas situações do que os terapeutas iniciantes. Embora essa possa ser uma questão de aprendizado, talvez também se relacione a forma como o supervisionando percebe a si mesmo, ao cliente e ao processo de forma mais global, tal qual a definição de supervisão fornecida por Távora (2002).

$\mathrm{O}$ estudo tem diversas limitações a serem mencionadas. Primeiro, uma vez que os questionários foram respondidos online, não há garantias quanto à veracidade da identificação dos respondentes. Adicionalmente, não há garantias de que aqueles que responderam o questionário eram de fato supervisores ou estagiários de Psicologia. Embora no banco de dados existam informações como $\mathrm{RG}, \mathrm{CPF}$, endereço de e-mail e instituição, essas informações não foram checadas, especialmente para resguardar o sigilo dos participantes.

Outra limitação clara está no fato de a amostra não ser representativa dos estudantes ou supervisores dos cursos de Psicologia do Brasil, como fica claro em sua descrição. Há concentrações de respondentes em algumas regiões do Brasil nas quais o estudo teve uma divulgação mais efetiva, contrapondo-se com a falta de respondentes em regiões mais afastadas. As concentrações observadas não se explicam pela variação do número de cursos de Psicologia, até mesmo porque elas são bastante distintas entre os grupos de supervisores e estagiários.

É importante ressaltar também que, apesar de terem sido comparados os pontos de vista de supervisores e estagiários, estes grupos não têm, necessariamente, ligação entre si. Ou seja, os grupos podem estar falando de supervisões diferentes.

\section{CONCLUSÃO}

Apesar das limitações encontradas, acreditamos que o estudo realizado contribui para a compreensão tanto do processo de supervisão como para a identificação de um aspecto negligenciado nos estudos sobre o funcionamento dos serviços-escola. Nesse sentido, reafirma-se ser a prática de supervisão uma importante situação de ensino e aprendizagem no contexto dos serviços-escola (Macedo \& Dockhorn, 2009). O resultado mais importante é que a supervisão é bem avaliada, de forma consistente, tanto por supervisores como por estagiários. Além disso, os pontos de discordância entre os grupos apontam para as áreas em que o processo de supervisão pode ser aprimorado assim como indica a pertinência de que pesquisas mais aprofundadas sobre o tema sejam realizadas.

\section{REFERENNCIAS}

Aguirre, A. B. (2000). A primeira experiência clínica do aluno: Ansiedades e fantasias presentes no atendimento e na supervisão. Psicologia: Teoria e Prática, 2(1), 3-31.

Ancona-Lopez, M. (1981). Avaliação de serviços de Psicologia clínica (Dissertação de mestrado). Pontifícia Universidade Católica de São Paulo; São Paulo.

Barreto, M. C., \& Barletta, J. B. (2010). A supervisão de estágio em Psicologia Clínica sob as óticas do supervisor e do supervisionando. Cadernos de Graduação-Ciências Biológicas e da Saúde, 12(12), 155-171.

Boeckel, M. G. et al. (2010). O papel do serviço-escola na consolidação do projeto pedagógico do curso de Psicologia. Psicol. Ensino \& Form [online], 1(1), 41-52. Retirado de http:// pepsic.bvsalud.org/scielo.php?script $=$ sci_arttext\&pid=S2177$20612010000100005 \& \operatorname{lng}=$ pt\&nrm=iso

Campezatto, P., \& Nunes, M. L. T. (2007). O atendimento em clínicas-escola de Psicologia da Região Metropolitana de Porto Alegre. Estudos de Psicologia, 24, 363-374.

Cheon, H.-S., Blumer, M. L., Shih, A.-T., Murphy, M., \& Sato, M. (2009). The influence of supervisor and supervisee matching, role conflict, and supervisory relationship on supervisee satisfaction. Contemporary Family Therapy, 31, 52-67.

Dobson, K. S., \& Shaw, B. F. (1993). The training of cognitive therapists: What Have we learned from treatment manuals? Psychotherapy, 30(4), 573-577.

Freitas, F. A., \& Noronha, A. P. (2007). Habilidades do psicoterapeuta segundo supervisores: diferentes perspectivas. PSIC, 8(2), 159-166.

Löhr, S. S., \& Silvares, E. F. M. (2006) Clínica-escola: integração da formação acadêmica com as necessidades da comunidade. In Silvares, E. F. M. (Org.). Atendimento Psicológico em clínicasescola (pp. 11-22). Campinas: Alínea.

Macedo, M. M. K., Baldo, M. A., Santos, R. L., Ribas, R. F., Silva, S. M., \& Goncalves, T. G. (2011). Motivos de busca de atendimento psicológico por adolescentes em uma clínica-escola. Revista de Psicologia: Teoria e Prática [online], 3, 63-75.

Macedo, M. M. K., \& Dockhorn, C. N. B. F. (2009). A Supervisão em Psicanálise: o fazer na clínica. In M. M. K. Macedo (Org.), Fazer Psicologia: uma experiência em clínica-escola (pp. 207219). São Paulo: Casa do Psicólogo.

Macedo, M. M. K., Nunes, M. L. T., Campezatto, P. M., \& Padilha, I. P. (2009). A clínica-escola SAPP e o fazer Psicologia. In M. M. K. Macedo (Org.). Fazer Psicologia: uma experiência em clínica-escola (pp. 17-41). São Paulo: Casa do Psicólogo.

Macedo, M. M. K., Silva, F. C. F., Giaretta, D. G., Ribas, R. F., \& Druck, C. M. (2010). Atenção integral à saúde masculina: a busca por atendimento psicológico em uma clínicaescola. Revista de Psicologia: Teoria e Prática [online], 12, 154-170. 
Melo, S. A., \& Perfeito, H. C. (2006). Características da população infantil atendida em triagem no período de 2000 a 2002 numa clínica-escola. Estudos de Psicologia, 23(3), 239-249.

Nigam, T., Cameron, P. M., \& Leverette, J. S. (1997). Impasses in the supervisory process: A resident's perspective. American Journal of Psychotherapy, 51(2), 252-272.

Oliveira-Monteiro, N. R., \& Nunes, M. T. (2008). Supervisor de Psicologia clínica: um professor idealizado? PsicoUSF, 13(2), 287-296.

Pretorius, W. M. (2006). Cognitive behavioural therapy supervision: recommended practice. Behavioural and Cognitive Psychotherapy, 34, 413-420.

Romaro, R. A., \& Capitão, C. G. (2003). Caracterização da clientela da clínica-escola de Psicologia da Universidade São Francisco. Psicologia: Teoria e Prática, 5(1), 111-121.

Silvares, E. F. (1993). O papel preventivo das clínicas-escola de Psicologia em seu atendimento a crianças. Temas em Psicologia, 2, 87-97.

Tavora, M. T. (2002). Um modelo de supervisão clínica na formação do estudante de Psicologia: A experiência da UFC. Psicologia em Estudo, 7(1), 121-130.
Autores:

Margareth da Silva Oliveira - Doutora, Pontifícia Universidade Católica do Rio Grande do Sul.

Rodrigo Fernando Pereira- Doutor, Universidade de São Paulo.

Ana Claudia Azevedo Peixoto - Doutora, Universidade Federal do Rio de Janeiro.

Marina Monzani da Rocha - Psicóloga, Doutora em Psicologia Clínica, Universidade Paulista (UNIP).

Nancy Ramacciotti de Oliveira-Monteiro - Psicóloga, Supervisora, Doutora em Psicologia, Universidade Federal de São Paulo (UNIFESP-BS).

Mônica Medeiros Kother Macedo - Psicóloga, Psicanalista, Doutora em Psicologia, Faculdade de Psicologia da Pontifícia Universidade Católica do Rio Grande do Sul (PUCRS).

Edwiges Ferreira de Mattos Silvares - Professora titular do Departamento de Psicologia Clinica do Instituto de Psicologia, Universidade de São Paulo (USP-SP).

Endereço para correspondência:

Margareth da Silva Oliveira

Faculdade de Psicologia - PUCRS

Av. Ipiranga, 6681 - Prédio 11, 9ํandar, sala 927

CEP 90619-900 Porto Alegre, RS, Brasil

E-mail:marga@pucrs.br

Recebido em: 21.10 .2013

Aceito em: 20.06.2014 